\title{
Factors Influencing the Morphological Characteristics of Village Chickens' Genetic Resources in the Abu-Dhabi Emirate, UAE
}

\author{
Mohammad J. Tabbaa1,2, Hussein H. Hassanin ${ }^{3}$ \\ ${ }^{1}$ RandD, Abu-Dhabi Food Control Authority, Abu-Dhabi, UAE \\ ${ }^{2}$ Department of Animal Production, School of Agriculture, The University of Jordan, Amman, Jordan \\ ${ }^{3}$ Animal Production, Abu-Dhabi Food Control Authority, Abu-Dhabi, UAE \\ Email: Mohm.tabbaa@ADFCA.AE
}

How to cite this paper: Tabbaa, M.J. and Hassanin, H.H. (2018) Factors Influencing the Morphological Characteristics of Village Chickens' Genetic Resources in the AbuDhabi Emirate, UAE. Open Journal of Animal Sciences, 8, 87-103.

https://doi.org/10.4236/ojas.2018.81007

Received: October 25, 2017

Accepted: January 9, 2018

Published: January 12, 2018

Copyright $\odot 2018$ by authors and Scientific Research Publishing Inc. This work is licensed under the Creative Commons Attribution International License (CC BY 4.0).

http://creativecommons.org/licenses/by/4.0/

\begin{abstract}
The study was accomplished to identify the characteristics of village chickens' (VCs) genetic resources in the Abu-Dhabi Emirate of United Arab Emirate (UAE) and to study factors affecting these characteristics. Each bird was individually observed, identified, measured and characterized of thirteen VCs pure breeds and crossbreds. The overall VCs had normal feather morphology (95.1\%) and distribution (77\%). Except for Fayomi chickens which were 100\% mottled, no specific plumage pattern was found. Almost 52\% of the VCs had white skins. Six different colors were reported for the shanks and maximized for white shanks (34.3\%). Large breasts (46\%) were more available. The predominant plumage color was mixed colors (37.5\%). Face size tended to be small $(42.8 \%)$ to medium (40.4\%). More brown (48.9\%) then orange $(27.3 \%)$ eyes were found. Dark (49.7\%) beaks were more available than white $(28.6 \%)$ or yellow (21.7\%) beaks. The distribution of wattle colors was similar to that of ear-lob colors with some variation. Small wattles (41.9\%) were most available. Single comb $(82.4 \%)$ is the most available; 11 other types and one with no comb were represented with low frequencies. In the whole sample, red and white combs (56.7\%) were the most available; however, plain red $(23.8 \%)$ and red and black (15.5\%) were represented. Results of factors influence showed that body weight was high significantly $(P<0.01)$ influenced by the interaction between both breed and region and breed and sex. Significant $(P<0.01)$ influence of interaction was observed between breed and location on body length, wing span and shank length. The interaction between breed and sex only significantly $(P<0.01)$ influenced shank length. Though, all main effects of breed, sex and region significantly $(P<0.01)$ influenced continuous measures. Most morphological characteristics were significantly $(P<0.01)$ different
\end{abstract}


among breeds. This study reported the morphological characteristics of the different VCs breeds kept in Abu-Dhabi Emirate, which considered the scientific base for future implementing of conservation and/or genetic improvement programs.

\section{Keywords}

Body Weight, Breeds, Morphological Characteristics, UAE, Village Chickens

\section{Introduction}

Village chickens (VCs) are those kept under traditional raising system and used for multiple purposes with variable morphological characteristics [1] [2] [3]. In many regions of the world, VCs are kept for several goals which include local consumption, extra income, pest control and manure production [4] [5] [6] [7]. They are more adaptive to their climatic harsh conditions, resistant to local diseases and classified by small size and low egg production [8] [9]. In addition, VCs are used to utilize farm by-products and mostly resistant to diseases and parasites [10] [11] [12]. In general, even if local breeds have low production rate, they are more adapted to their environment and they may reserve an essential and special genes or traits that could meet the changeable preferences of consumers, alteration of production systems, and resistance to newly developing diseases [13]. Consequently, VCs are gene reservoirs for genetic future studies, improvement and conservation [3] [6].

The breed characteristics are considered as an important key for decision-making guide in livestock improvement, breeding programs and conservation [14] [15]. Characterization using molecular genetics provides trustworthy data though it is complex and expensive and should be always incorporated with phenotypic characteristics to be useful [13] [16]. In terms of morphological characteristics, the phenotypic traits of VCs may be considered to indicate the local chickens of the United Arab Emirates (UAE). Other characteristics like reproductive efficiency, egg production and body weight may be considered for specifying the VCs of the UAE. Most of these traits may have a direct or indirect influence on the marketability of chickens [17]. Qualitative and quantitative measurements can be determined by using FAO checklist for chickens' phenotypic characterization. There are many important traits like plumage color, feathers, skin color, shank color, ear lobe color, eye color, and comb type as examples of qualitative variables [1]. The morphological characteristics can clarify the correlation between the phenotypic traits and the production status of the VCs. Also, qualitative morphological characteristics assist in describing genetic variations, adaptive attributes, and have economic value in chickens [18]. The guidelines may also be useful to decision-makers who wish to obtain a better understanding about the potential contributions of phenotypic characterization studies to national policies and programs for animal genetic resources and of the practicali- 
ties involved in implementing such studies [1]. No studies available in the UAE consider characterization of local breeds of chicken. Characterization of local breeds is the first step for future genetic improvement program in Abu-Dhabi. Therefore, the objectives of this study were to identify the characteristics of village chickens' genetic resources in the Abu-Dhabi Emirate of UAE and to study factors affecting these chicken's characteristics.

\section{Materials and Methods}

\subsection{The Study Area}

The study was accomplished between March 2015 and June 2016, in 18 randomly selected villages belong to Abu-Dhabi in UAE, located between $22^{\circ} 40^{\prime \prime}$ and $25^{\circ} \mathrm{N}$ and $51^{\circ}$ and $56^{\circ} \mathrm{E}$. The 18 randomly selected villages were located in each of the 3 Abu-Dhabi Emirate municipalities (Abu-Dhabi (6), Al-Ain (8) and Al-Dhafra (4)). The UAE's weather is characterized by hot desert climate, with mostly clear skies all-year-round and low rainfall. Average maximum temperature is above $39^{\circ} \mathrm{C}$ with high humidity during the period from June to September, while cool temperature reaches $19^{\circ} \mathrm{C}$ from November to March.

\subsection{Sampling Procedures}

Households within Abu-Dhabi Emirate who raise more than 10 VCs and willing to participate in the study were randomly selected. Chicken keepers who keep VCs under traditional system of raising for multiple purposes, regardless of the flock size were considered in the study. The sampling size of each farm was 5 10 adult hens and $2-5$ adult cocks ( $>6$-month-old) from each breed, with a total of 1208 chickens from a stratified random sampling procedure of 59 chicken keepers in the three municipal regions (Abu-Dhabi (20), Al-Ain (28) and Al-Dhafra (11)). The sample represents around $10 \%$ of the expected size of chicken keepers' population (Animal Wealth Division, Abu-Dhabi Food Control Authority, Personal communication).

\subsection{Data Collection}

A survey was conducted to study the VCs populations of Abu-Dhabi Emirate. Assigning names to breeds of chicken were accomplished based on keepers' perceptions and, explicit phenotypic differences among and consistencies within group and was partly based on the popular usage of particular name. The morphological characteristics of each bird were individually observed according to [1] checklist for phenotypic characterization of chickens as follow: Feather morphology (normal, frizzle, silky); feather distribution (normal, naked neck, feathered shanks and feet, muffs and beard, crest and vulture hocks (long stiff feathers protruding down and back from the hock joint)); plumage pattern (plain, barred, laced, mottled); plumage color (white, black, blue, red, wheaten. Skin color: not pigmented (white), yellow, blue-black); shank color (white, yellow, blue, green, black, brown); ear-lobe color (not pigmented (white), red, 
white and red); comb type (single, pea, rose, walnut, cushion, strawberry, duplex, V-shaped, double); comb size (small, medium, large); eye color (pearl, brown, orange, red, black); body weight, body length (length between the tip of the rostrum maxillae (beak) and that of the cauda (tail, without feathers) with bird's body was completely drawn throughout its length); shank length (length in $\mathrm{cm}$ of the shank from the hock joint to the spur of either leg); and wing span (length in $\mathrm{cm}$ between tips of right and left wings after both were fully stretched out).

\subsection{Statistical Analysis}

Statistical analysis was performed on qualitative survey data using the Chi-square test of the FREQ procedure [19]. Least square analysis of variance was utilized to study the effect of region, sex and breed of chicken on quantitative data using GLM procedure [19]. All possible interactions were also tested though only their two-way interactions were left in the final statistical model. Means for significant effects were compared at $P<0.05$ using t-test and standard errors calculated using GLM procedure [19] were presented in the Tables.

\section{Results and Discussion}

The UAE is an open country for animal genetic resources exchange throughout no restriction for people of Emirates to import animals and birds breeds from all over the world. Emirati people are interested in keeping robust birds that would rank high in exhibitions and competitions. These chickens are source of income for many Emirati families beside home consumption and reared for meat and egg production [7]. Therefore, 13 VCs breeds in addition to crossbreds were found in this study (Table 1). The most available breed was the Emirati local chickens breed which sometimes called (Addar chickens) and was found in 71\% of the properties. The population was observed to be highly diverse breed comes with many morphology and plumages, all given the same name. The direct consequences of the diversified phenotypic characteristics of the Emirati local VCs indicate high potential for genetic improvement. Therefore, this enormous gene pool should be conserved from extinction or inbreeding and genetic drift and be used for genetic improvement through individual selection with application of molecular technology, incorporating production objectives and preferred characteristics of the local Emirati people [3] [8] [20]. The extinction of the local breeds could happen due to arbitrary crossbreeding and breed replacement [3]. Since extinction is an irreversible process, precautions should be taken before permanent losses of the indigenous animal genetic resources [21]. Although, indigenous chickens (genotypes) were known as less productive, keepers prefer them, as they were more adapted to severe environmental conditions, have better maternal care, and produce leaner and tastier meat compared to exotic breeds [7] [22]. The second most available breed was Fancy or what is locally called French breed which was found in $36 \%$ of the properties. Though, the 
Table 1. Body weight in grams ( \pm standard error) of chicken as affected by the interactions of breed and region and of breed and sex of chicken.

\begin{tabular}{|c|c|c|c|c|c|c|}
\hline \multirow{2}{*}{ Breed } & \multirow{2}{*}{$\begin{array}{c}\text { Frequency } \\
\%\end{array}$} & \multicolumn{3}{|c|}{ Breed $^{\star}$ Region } & \multicolumn{2}{|c|}{ Breed $^{*}$ Sex } \\
\hline & & Abu-Dhabi & Al-Ain & Al-Dhafra & Female & Male \\
\hline$P$-value & & & $<0.0001$ & & \multicolumn{2}{|c|}{0.0007} \\
\hline $\mathrm{N}$ & 1208 & 417 & 587 & 204 & 831 & 377 \\
\hline Local & 71.19 & $1357 \pm 28 \mathrm{i}$ & $1423 \pm 23 i$ & $1722 \pm 50 \mathrm{cdef}$ & $1288 \pm 21 f$ & $1575 \pm 31 \mathrm{de}$ \\
\hline Fancy & 35.59 & $2119 \pm 30 b$ & $2106 \pm 40 \mathrm{~b}$ & $1677 \pm 96 \mathrm{efg}$ & $1819 \pm 28 b c$ & $2359 \pm 43 a$ \\
\hline Crossbred & 20.34 & $1551 \pm 54 \mathrm{gh}$ & $1706 \pm 49 \mathrm{def}$ & $1686 \pm 49 \mathrm{defg}$ & $1431 \pm 37 \mathrm{de}$ & $1876 \pm 51 b$ \\
\hline Omani & 11.86 & & $1388 \pm 44 \mathrm{i}$ & & $1274 \pm 50 \mathrm{f}$ & $1502 \pm 78 \mathrm{de}$ \\
\hline Pakistani & 10.17 & & $2210 \pm 280 \mathrm{abcdef}$ & $1935 \pm 101 \mathrm{bce}$ & $1596 \pm 112 \mathrm{cde}$ & $2320 \pm 174 a$ \\
\hline Brahman & 8.47 & $1960 \pm 144 \mathrm{bcdef}$ & $2547 \pm 186 a$ & $1116 \pm 99 j$ & $1528 \pm 86.83 \mathrm{de}$ & $1514.29 \pm 147 \mathrm{def}$ \\
\hline Kuwaiti & 6.78 & $981 \pm 132 j$ & $1173 \pm 77 j$ & & $1050 \pm 87 \mathrm{~g}$ & $1200 \pm 112 \mathrm{fg}$ \\
\hline Fayomi & 3.39 & & & $1635 \pm 101 \mathrm{fg}$ & $1500 \pm 123 \mathrm{def}$ & $1770 \pm 174 \mathrm{bcd}$ \\
\hline Kerala & 3.39 & $1783 \pm 154$ cdefg & $1305 \pm 117 \mathrm{hij}$ & & $1344 \pm 129$ efg & $1614 \pm 147 \mathrm{bcde}$ \\
\hline Other breeds ${ }^{1}$ & 8.47 & & $1676 \pm 65 f g$ & $1718 \pm 73 \mathrm{cdefg}$ & $1514 \pm 58 \mathrm{de}$ & $1874 \pm 89 b c$ \\
\hline
\end{tabular}

${ }^{1}$ Other breeds: uncommon breeds that were named Holland, Australian, Japanese, Habhab and Abu-Dhabi. a,b,c,d Different superscripts within an interaction indicate significant differences $(P<0.05)$.

breed was not similar to any of the known French breeds, however, because fancy sound like French in Arabic most keepers called this breed as French. The Fancy breed was of two colors, one of which was very similar to New Hampshire Red, and the second was very similar to Delaware breed. Though, both had similar body conformation and body weight. They were preferred by local Emirati people because of their fast growth rate and final body weight. The third was the crossbred chickens (20\%), which mainly crossed with Fancy breed, secondly with Pakistani and then with all other breeds. The fourth was the Omani chickens (12\%) which were highly diverse group of chickens, very similar to the Emirati local breed, a little shorter, and found only in Al-Ain close to Oman boarder. The fifth breed was the Pakistani chickens (10\%) which were originally from Pakistan and characterized by long body with divers colors and most shapes characteristics. Brahman chickens were mostly crested heads, brown and creamy in color with very diverse comb types. Other breeds were found in less than $10 \%$ of the visited sample farms. Kuwaiti chickens were originally from Kuwait had very small body size and weight, variable in colors and shapes characteristics. In $\mathrm{Ku}-$ wait, it is traditionally called the Arabi chickens and it is important as a source of meat and eggs and used for entertainment [23]. Arabi chickens in Kuwait are highly resistant to the adverse environmental conditions and are characterized with medium body size, crested heads, V-shaped comb, short and dark shanks and multi-colored [23]. Fayomi chickens were a highly homogeneous group of chickens. All Fayomi chickens had normal feather morphology and distribution with mottled plumage pattern and single comb. Kerala chickens were characte- 
rized with frizzle feather and mostly with single comb. Other breeds were each found in only one of the sampled farms. These were named as Holland, Australian, Japanese, Habhab and Abu-Dhabi chickens. They were grouped together because they have very similar characteristics, very little differences and very few in numbers. They are reported in this study because it is the first in the UAE.

\subsection{Quantitative Morphological Characteristics}

Body weight was highly significantly $(P<0.01)$ influenced by the interaction between both breed and region and breed and sex (Table 1). All main effects were also highly significant $(P<0.01)$, however, the three-way interaction was not significant $(P>0.1)$. Body weight differences are due to differences in body size and condition score of the bird [12]. Al-Dhafra region has the heaviest Emirati local breed, while Fancy breed was heavier in both Abu-Dhabi and Al-Ain than that of Al-Dhafra. Brahman was the heaviest breed in Al-Ain and was the least in Al-Dhafra, while Kuwaiti breed had the lightest body weight. Similarly, many researchers reported significant differences in body weight due to location for the same and different breeds in different countries [2] [12] [13] [20]. Although, Kuwaiti chickens were very small, many people prefer them as game birds. Small body size is a promising character because it decreases feed requirements for maintenance and increase feed efficiency [15].

Males were always heavier than females, differences were not consistent among breeds; male-female differences within some breeds were not significant $(P>0.05$, Table 1$)$. Similarly, influence of sex of chickens on body weight favoring males was reported by many [3] [12] [18]. Body weight advantage of males over that of females particularly at birth is due to fetal hormones which sustain higher skeletal growth in males, in addition to longer gestation period in males [12]. Although were significantly different, the average body weights reported for males' and females' Kuwaiti chickens in Kuwait were much smaller than that in this study [23].

The significant $(P<0.01)$ influence of interaction between breed and location on body length, wing span and shank length were presented in Table 2, while the interaction between breed and sex was only significantly $(P<0.01)$ influenced shank length (Table 3 ). Though, all main effects of breed, sex and region significantly $(P<0.01)$ influenced body length, wing span and shank length. Comparably, [2] reported that shank length, body length and wing span were different among different sub-populations of chickens of different breeds and regions. Region influence was reported to have effect on body length [12], while breed-location interaction was reported to have influence on shank length [2] [18] [20]. Males had mostly higher values than that for females (Table 3). Similarly, [12] and [18] have shown that males have larger values for body length and shank length. However, [3] reported that although males have larger values of wing and shank lengths, differences were not significant. Fayomi had similar body length for both sexes while Brahman has similar wing span for both sexes. 
Table 2. Body length, wing span and shank length ( \pm standard error) of chicken as affected by the interaction of breed and region.

\begin{tabular}{|c|c|c|c|c|c|c|c|c|c|}
\hline \multirow{2}{*}{ Breed } & \multicolumn{3}{|c|}{ Body length } & \multicolumn{3}{|c|}{ Wing span } & \multicolumn{3}{|c|}{ Shank length } \\
\hline & Abu-Dhabi & Al-Ain & Al-Dhafra & Abu-Dhabi & Al-Ain & Al-Dhafra & Abu-Dhabi & Al-Ain & Al-Dhafra \\
\hline$P$-value & & $<0.0001$ & & & $<0.0001$ & & & 0.0005 & \\
\hline Local & $39.61 \pm 0.23 \mathrm{gh}$ & $39.7 \pm 0.2 \mathrm{gh}$ & $41.8 \pm 0.4 \mathrm{de}$ & $41.4 \pm 0.3 \mathrm{~h}$ & $42.8 \pm 0.2 \mathrm{fg}$ & $45.0 \pm 0.5 c$ & $5.6 \pm 0.1 \mathrm{~g}$ & $5.7 \pm 0.1 \mathrm{fg}$ & $6.1 \pm 0.1 \mathrm{bde}$ \\
\hline Fancy & $44.68 \pm 0.24 b$ & $44.6 \pm 0.3 \mathrm{~b}$ & $44.6 \pm 0.8 \mathrm{~b}$ & $47.4 \pm 0.3 \mathrm{a}$ & $48.1 \pm 0.4 \mathrm{a}$ & $38.1 \pm 1.0 \mathrm{jk}$ & $6.8 \pm 0.1 \mathrm{ac}$ & $6.6 \pm 0.1 b c$ & $7.1 \pm 0.2 \mathrm{a}$ \\
\hline Crossbred & $42.73 \pm 0.43 c d$ & $42.8 \pm 0.4 \mathrm{~cd}$ & $44.2 \pm 0.4 \mathrm{~b}$ & $44.1 \pm 0.6 \mathrm{cde}$ & $46.9 \pm 0.5 \mathrm{ab}$ & $43.5 \pm 0.5 \mathrm{defg}$ & $6.7 \pm 0.1 \mathrm{abc}$ & $6.3 \pm 0.1 \mathrm{bd}$ & $6.4 \pm 0.1 \mathrm{bd}$ \\
\hline Omani & & $40.3 \pm 0.4 \mathrm{fg}$ & & & $42.3 \pm 0.5 \mathrm{fgh}$ & & & $5.4 \pm 0.1 \mathrm{~h}$ & \\
\hline Pakistani & & $49.6 \pm 2.3 \mathrm{a}$ & $44.8 \pm 0.8 \mathrm{~b}$ & & $51.0 \pm 2.9 \mathrm{ab}$ & $41.4 \pm 1.0 \mathrm{ghi}$ & & $7.1 \pm 0.6 \mathrm{abc}$ & $6.3 \pm 0.2 \mathrm{bd}$ \\
\hline Brahman & $44.44 \pm 1.16 \mathrm{bc}$ & $44.9 \pm 1.5 \mathrm{abc}$ & $38.1 \pm 0.8 \mathrm{~h}$ & $48.4 \pm 1.5 \mathrm{ab}$ & $49.8 \pm 1.9 \mathrm{a}$ & $33.1 \pm 1.01$ & $6.2 \pm 0.3$ bdefg & $5.7 \pm 0.4 \mathrm{defgh}$ & $6.4 \pm 0.2 \mathrm{bcd}$ \\
\hline Kuwaiti & $34.77 \pm 1.06 \mathrm{i}$ & $35.4 \pm 0.6 \mathrm{i}$ & & $38.5 \pm 1.4 \mathrm{ijk}$ & $37.8 \pm 0.8 \mathrm{k}$ & & $4.5 \pm 0.3 \mathrm{i}$ & $4.3 \pm 0.2 \mathrm{i}$ & \\
\hline Fayomi & & & $40.4 \pm 0.8 \mathrm{efgh}$ & & & $42.1 \pm 1.0 \mathrm{efgh}$ & & & $7.0 \pm 0.2 \mathrm{ac}$ \\
\hline Kerala & $42.53 \pm 1.24 \mathrm{bcdef}$ & $38.3 \pm 0.9 \mathrm{~h}$ & & $46.1 \pm 1.6 \mathrm{abcd}$ & $40.7 \pm 1.2 \mathrm{ghij}$ & & $6.5 \pm 0.3 \mathrm{abcd}$ & $5.4 \pm 0.3 \mathrm{gh}$ & \\
\hline $\begin{array}{c}\text { Other } \\
\text { breeds }^{1}\end{array}$ & & $41.2 \pm 0.5 \mathrm{ef}$ & $41.1 \pm 0.6 \mathrm{ef}$ & & $43.0 \pm 0.7 \mathrm{defg}$ & $45.3 \pm 0.8 b c$ & & $5.3 \pm 0.1 \mathrm{~h}$ & $5.8 \pm 0.2 \mathrm{efg}$ \\
\hline
\end{tabular}

${ }^{1}$ Other breeds: uncommon breeds that were named Holland, Australian, Japanese, Habhab and Abu-Dhabi. a,b,c,d Different superscripts within an interaction indicate significant differences $(P<0.05)$.

Table 3. Body length, wing span and shank length ( \pm standard error) of chicken as affected by the interaction of breed and sex of chicken.

\begin{tabular}{ccccccc}
\hline \multirow{2}{*}{ Breed } & \multicolumn{2}{c}{ Body length } & \multicolumn{2}{c}{ Wing span } & \multicolumn{2}{c}{ Shank length } \\
\cline { 2 - 7 } & Female & Male & Female & Male & Female & Male \\
\hline P-value & \multicolumn{2}{c}{0.1027} & & 0.3371 & & 0.0005 \\
Local & $38.0 \pm 0.2 \mathrm{hi}$ & $41.8 \pm 0.2 \mathrm{~d}$ & $40.1 \pm 0.2 \mathrm{fghi}$ & $45.0 \pm 0.3 \mathrm{~cd}$ & $5.2 \pm 0.1 \mathrm{~h}$ & $6.2 \pm 0.1 \mathrm{de}$ \\
Fancy & $42.1 \pm 0.2 \mathrm{~cd}$ & $47.2 \pm 0.3 \mathrm{a}$ & $44.3 \pm 0.3 \mathrm{~d}$ & $49.9 \pm 0.5 \mathrm{a}$ & $6.2 \pm 0.1 \mathrm{de}$ & $7.3 \pm 0.1 \mathrm{a}$ \\
Crossbred & $40.8 \pm 0.3 \mathrm{ef}$ & $45.7 \pm 0.4 \mathrm{~b}$ & $41.8 \pm 0.4 \mathrm{efg}$ & $47.9 \pm 0.6 \mathrm{~b}$ & $6.0 \pm 0.1 \mathrm{e}$ & $6.9 \pm 0.1 \mathrm{bc}$ \\
Omani & $37.88 \pm 0.4 \mathrm{hi}$ & $42.8 \pm 0.6 \mathrm{~cd}$ & $40.4 \pm 0.5 \mathrm{fghi}$ & $44.2 \pm 0.8 \mathrm{~cd}$ & $5.1 \pm 0.1 \mathrm{~h}$ & $5.6 \pm 0.2 \mathrm{fg}$ \\
Pakistani & $43.0 \pm 0.9 \mathrm{~cd}$ & $47.4 \pm 1.4 \mathrm{ab}$ & $40.1 \pm 1.2 \mathrm{fghi}$ & $44.2 \pm 1.9 \mathrm{bcdef}$ & $6.0 \pm 0.2 \mathrm{ef}$ & $6.8 \pm 0.4 \mathrm{abcd}$ \\
Brahman & $39.1 \pm 0.7 \mathrm{gh}$ & $42.2 \pm 1.2 \mathrm{cdef}$ & $39.1 \pm 0.9 \mathrm{i}$ & $39.5 \pm 1.6 \mathrm{fghij}$ & $6.3 \pm 0.2 \mathrm{de}$ & $6.2 \pm 0.3 \mathrm{def}$ \\
Kuwaiti & $33.8 \pm 0.7 \mathrm{j}$ & $36.7 \pm 0.9 \mathrm{i}$ & $36.4 \pm 0.9 \mathrm{j}$ & $39.6 \pm 1.2 \mathrm{fghi}$ & $4.2 \pm 0.2 \mathrm{j}$ & $4.5 \pm 0.2 \mathrm{ij}$ \\
Fayomi & $39.4 \pm 1.0 \mathrm{fgh}$ & $41.3 \pm 1.4 \mathrm{cdefg}$ & $39.1 \pm 1.3 \mathrm{ghij}$ & $45.0 \pm 1.9 \mathrm{bcde}$ & $7.0 \pm 0.3 \mathrm{abc}$ & $7.0 \pm 0.4 \mathrm{abcd}$ \\
Kerala & $36.9 \pm 1.0 \mathrm{hi}$ & $42.7 \pm 1.2 \mathrm{cde}$ & $39.5 \pm 1.4 \mathrm{ghij}$ & $45.8 \pm 1.6 \mathrm{bcd}$ & $5.2 \pm 0.3 \mathrm{ghi}$ & $6.4 \pm 0.3 \mathrm{cde}$ \\
Other breeds ${ }^{1}$ & $38.8 \pm 0.5 \mathrm{gh}$ & $43.5 \pm 0.7 \mathrm{c}$ & $41.4 \pm 0.6 \mathrm{efgh}$ & $46.6 \pm 1.0 \mathrm{bc}$ & $5.1 \pm 0.1 \mathrm{~h}$ & $5.9 \pm 0.2 \mathrm{ef}$ \\
\hline
\end{tabular}

${ }^{1}$ Other breeds: uncommon breeds that were named Holland, Australian, Japanese, Habhab and Abu-Dhabi. a,b,c,d Different superscripts within an interaction indicate significant differences $(P<0.05)$.

Shank length was not different between sexes for each of Brahman, Kuwaiti and Fayomi. Pakistani breed in Al-Ain had the longest body and wing span, with long shanks. Body length was consistently second for Fancy in all locations while Brahman body length was similar in Abu-Dhabi and Alain and was lower in Al-Dhafra. Kuwaiti as usual had consistently the shortest body. Wing span of Brahman and Fancy in Abu-Dhabi and Alain were similar to that of Pakistani in 
Al-Ain, however, these breeds had lower values in Al-Dhafra. Similarly, [3] reported that wing span was a major discriminant among different genetic groups. Shank length was not consistent for almost all breeds in different locations.

\subsection{Qualitative Morphological Characteristics}

Emirati local chickens and the overall VCs in the Emirate had normal feather morphology (95.1\%), with other morphology types were represented, however, differences among breeds were highly significant $(P<0.01$, Figure 1$)$. Village chickens in Philippines had normal feather morphology [13], while that of VCs feathers in Ethiopia was silky [18] and that in Sri Lanka was variety of morphologies [3]. Morphological variations are maybe due to variations in single qualitative genes in the VCs gene pool [3] [8]. Pakistani, Fayomi and rare chicken breeds were all with 100\% normal feather morphology, while Kuwaiti chickens had only $87.5 \%$ of normal feather morphology and the other $12.5 \%$ had silky feather. $100 \%$ of Kerala chickens had frizzle feather.

In general, $77 \%$ of all chicken breeds had normal feather distribution, while feathered shanks and feet and crested head each represent $10 \%$ of the sampled

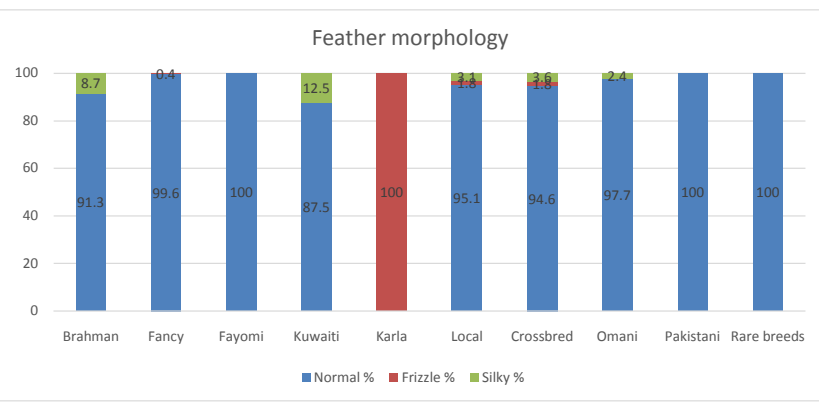

Feather distribution

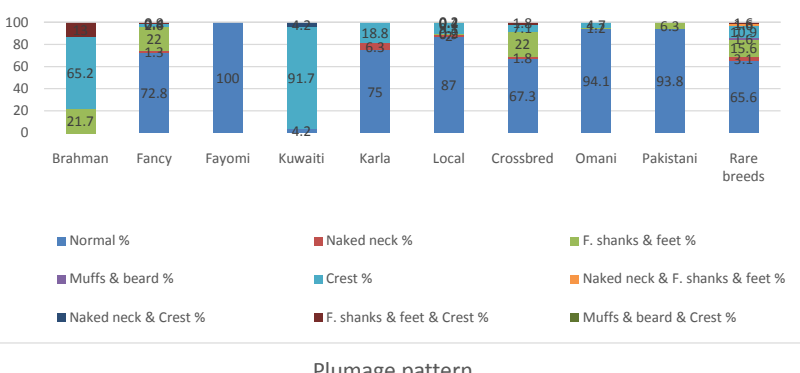

Plumage pattern

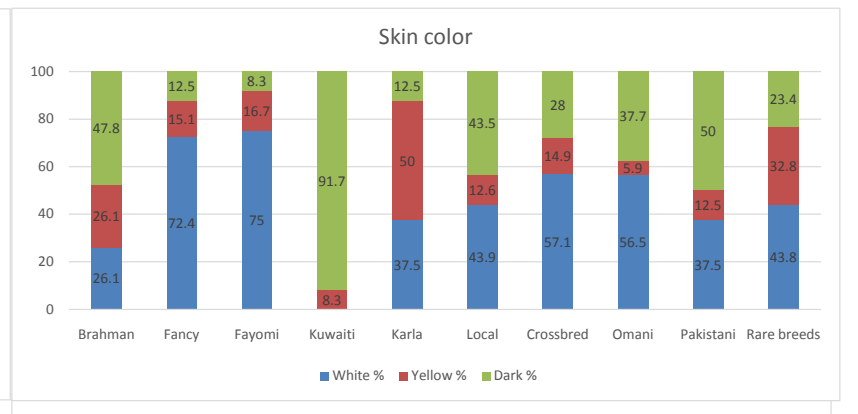

Shank color

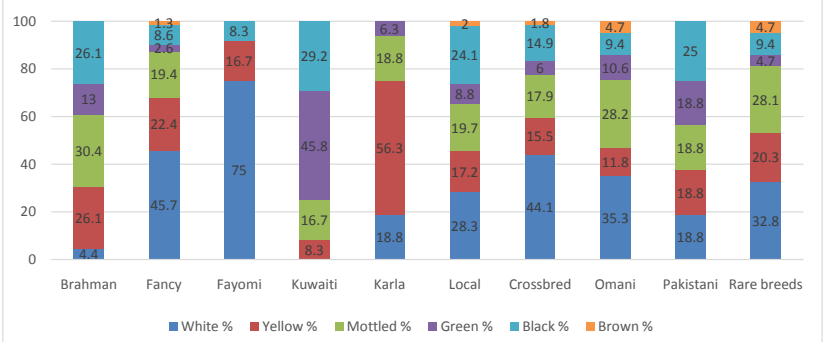

Breast size

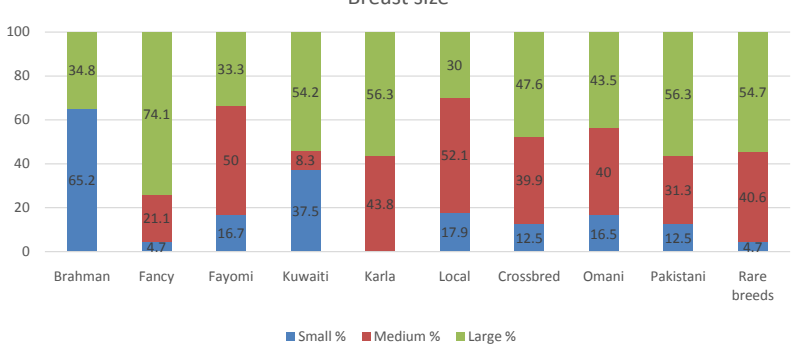

Figure 1. Feather morphology and distribution, plumage pattern breast size, skin and shank color as affected by breed of chicken. P-value for the chi-square test $(P<0.001)$. Other breeds: uncommon breeds that were named Holland, Australian, Japanese, Habhab and Abu-Dhabi. 
chicken population. Contrary to this result, [9] observed absence of feather on shanks in Bhutan VCs. However, each breed had significantly different values $(P$ $<0.01)$. For instance, $87 \%$ of Emirati local chickens had normal feather distribution with $9 \%$ of crested heads, while $100 \%$ of Fayomi had normal distribution. On the other hand, around $92 \%$ and $65 \%$ of each of Kuwaiti and Brahman, respectively, had crested heads. High diversity of feather distributions in VCs within and among different countries [3] [8] [9] [18] [20]. Although, naked neck gene is a dominant gene and is responsible for loss of feather in neck region [24], naked neck distribution of feather in this study was very low $(2.3 \%$ in the overall VCs). Similar result was observed by [18] in Ethiopia. Furthermore, naked neck gene may increase feed efficiency, growth rate, disease resistance and has desirable effects on heat tolerance and adult fitness [18] [25]. However, farmers maybe did not favor the naked neck chickens and select against this gene, which make it at risk of extinction unless actions are made to genetically conserve it [18].

Except for Fayomi chickens which were 100\% mottled, no specific plumage pattern was found for the whole population. Though, the mottled pattern was main pattern with $58.5 \%$ of the population, followed by barred $(21.5 \%)$, plain (13.3\%) and laced (6.8\%) patterns, however, different breeds had different distribution of plumage patterns $(P<0.01)$. The Local breed had mottled pattern represented by almost $50 \%$, with the presence of other patterns. Fancy, Omani, Kerala and rare breeds had mainly mottled pattern of $81 \%, 43.5 \%, 50 \%$ and $75 \%$, respectively. On the other hand, Pakistani, Brahman and Kuwaiti had mainly barred pattern with $43.8 \%, 56.5 \%$ and $79.2 \%$, respectively. On the other hand, researcher in different parts of the world reported that no specific plumage pattern found for the majority of their sampled VCs [3] [15].

Almost $52 \%$ of the overall sampled population of VCs had white or not pigmented skins; dark skinned chickens represent one third (33.3\%) of the population and the rest had yellow skin (15\%), though, differences among breeds were significant $(P<0.01)$. Emirati local chickens skin color was ranging from white (44.9\%) to yellow (12.6\%) to dark skin $(43.5 \%)$. Fancy and Fayomi skins were mostly white $(72.4 \%, 75 \%$, respectively), while Kuwaiti chicken skins were mostly dark (91.7\%). However, different regions of Ethiopia had differences in the majority of skin color either white or yellow [2] [18]. Presence of carotenoid pigments causes the yellow skin color, which is due to homozygous recessive alleles causing the inhibition of expression of the beta-carotene dioxygenase- 2 enzyme while white birds are carrying the dominant allele [2]. Cabarles [13] reported low diversity of skin colors within genetic groups in Philippines. Kosba1 et al. [20] observed differences of VCs skin colors influenced by region of the country.

Six different colors were found for the chicken shanks, with $34.3 \%$ of the sampled population had white or not pigmented shanks; in addition to $18.4 \%$ had yellow shanks (Figure 1). Researchers in other parts of the world reported diversity of shank colors for VCs [3] [9] [12] [15] [20]. Differences in shank color were highly significant $(P<0.01)$ among different breeds of VCs. All shank col- 
ors were represented in the Local chicken breed. Fayomi had 75\% white shanks, while Kuwaiti had no white shanks. Cabarles [13] observed high diversity of shank color ranged among groups of VCs but not within groups. Genes responsible for shank color also affect plumage color [9].

Breast size relative to body was tended to be large (46\%) to medium (39.5\%, Figure 1). Distribution of breast size was significantly $(P<0.01)$ different among different breeds. Breast size in the Emirati local chickens was ranging from small to large with highest percentage for the medium size (52.1\%). Fancy breed had the highest large breast frequency (74.1\%) among all breeds, while Brahman had the highest small breast frequency (65.2\%). In Sri Lanka breast size measured by circumference had low variability within groups and can be used to characterize different phenotypic groups with males always having larger values for body circumference [3]. Breast size and skin color are two economically important traits, since breast meat is more expensive and preferable by many people and they do not like the dark-skinned chickens. However, some people consider chicken with dark skins as more natural.

\section{Feather color}

The color variations among and within local breeds of VCs in UAE were attracting poultry fanciers that were interested in selection of showy and colorful birds. Feather color of various body parts of the sampled chickens were highly significant $(P<0.01)$ among different breeds (Figure 2$)$. The predominant plumage color for the overall sampled population of VCs was mixed colors (37.5\%), the same ratio was found in Emirati local chickens, also in Fancy (42.7\%), Omani (40\%), Fayomi (66.7\%) and rare breeds (45.3\%) chickens were dominated with mixed colors plumage. The next color was the brown and cream color (24.3\%), which was predominant in Pakistani (43.8\%), Brahman (73.9\%), Kuwaiti (50\%) and Kerala (25\%) chickens. The third overall wide spread color was black and brown (15.9\%). Other colors were found with low frequencies on the overall. Researchers observed high variability in plumage color among and within breeds of VCs in some countries worldwide [3] [8] [12] [15]. This might be due to that several genes interact to determine plumage colors and VCs were not selected for these traits [2] [12]. However, other researchers reported the predominance of certain colors in plumage in each genetic group VCs, which could be due to selection preferences of keepers [9] [13] [18]. Hackle or neck feather color was highly variable within and among breeds with reddish-brown having the highest frequency of less than $22 \%$ in the overall. Emirati local, Fancy, Omani, Kerala and Kuwaiti chickens' breeds had all range of colors for the hackle feathers (Figure 2). On the other hand, 75\% Fayomi had reddish brown hackle feathers, while other breeds had medium variability. Breast feather also had high variability, however, in the overall, brown and cream color had the highest frequency (31.6\%), with all other colors were represented by less than $15 \%$ (Figure 2). Though, lower variability was observed within breed. Brahman had $65.2 \%$ brown and cream breast and Fayomi had 75\% light brown. Similarly, wing coverts feathers were brown and cream (26.9\%), with all other colors were 


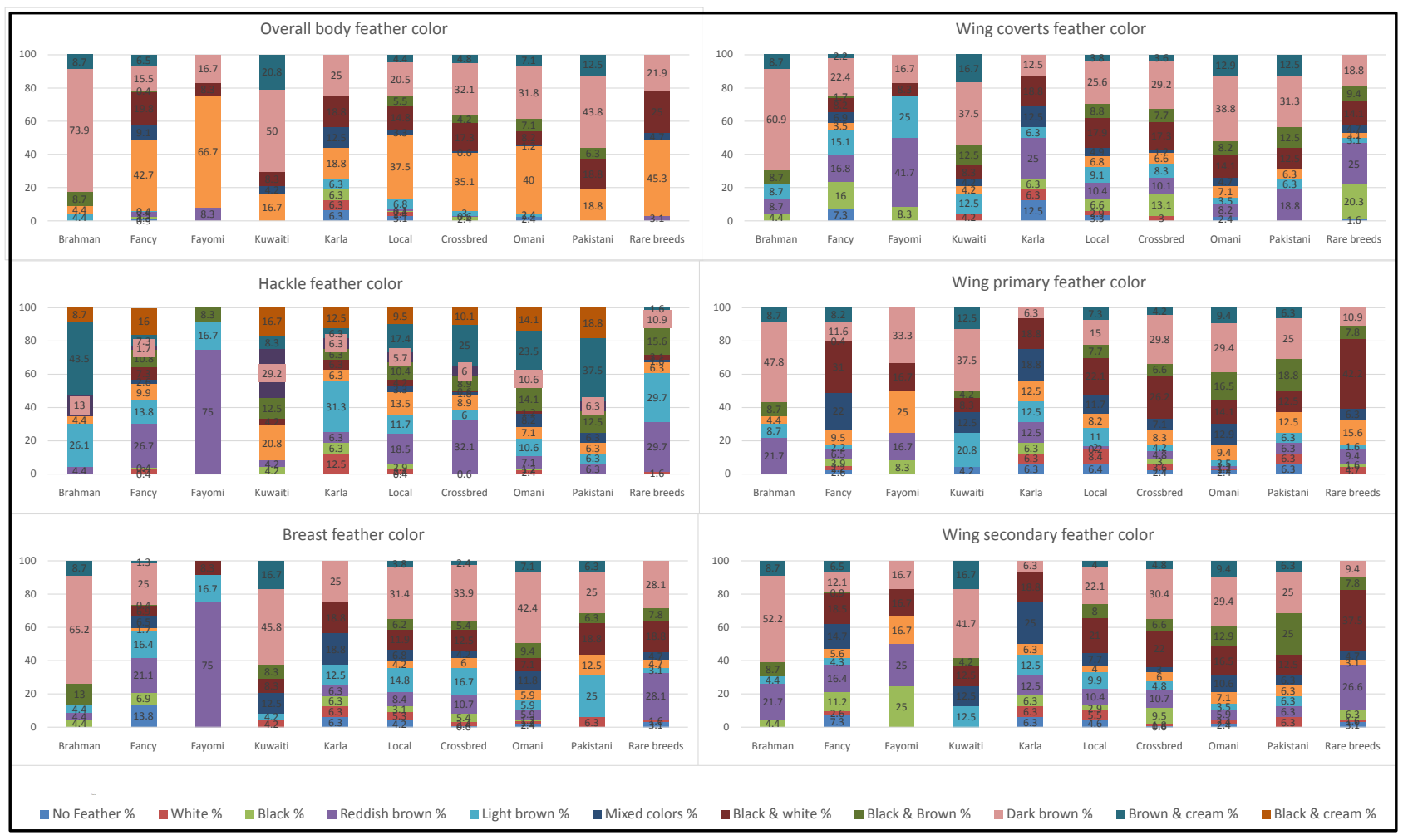

Figure 2. Feather color of various body parts of the sampled chickens. P-value for the chi-square test $(P<0.001)$. Other breeds: uncommon breeds that were named Holland, Australian, Japanese, Habhab and Abu-Dhabi.

represented by less than $15 \%$ in the overall (Figure 2). Brahman had $60.9 \%$ brown and cream breast while Fayomi had only $41.7 \%$ light brown wing coverts feathers. Wing primary and secondary feathers were more of brown and black, or brown and cream colors (Figure 2). However, each breed had its own more frequent color represented, with high variability in almost all VCs breeds. This was also true for the Emirati local breed, which was more variable in various body parts feathers, even more than other breeds.

\section{Head characteristics}

Figure 3 shows various head characteristics which were all highly significantly $(P<0.01)$ different for the different breeds of VCs. In the overall, face size tended to be small (42.8\%) to medium (40.4\%). Emirati local, Fancy and Omani breeds, in addition to, the crossbreds had similar values for the frequency of the different face size classes. However, other breeds had different frequencies; Pakistani $(50 \%)$ and Kerala (75\%) chickens tended to have medium face sizes, while Brahman (73.9\%) and Kuwaiti (83.3\%) tended to have small face sizes. Fayomi had only small (41.7\%) or medium (58.3\%) size faces (Figure 3).

The overall eye color was more of brown $(48.9 \%)$ or orange $(27.3 \%)$. Other colors frequencies such as pearl, red and black were less than $10 \%$. Emirati local, Fancy, Omani, Kerala, crossbreeds and rare breeds had similar values for the frequency of the different eye colors. However, $62.5 \%$ of Pakistani chickens had orange eyes, $82.6 \%$ of Brahman and $83.3 \%$ of Fayomi had brown eyes, and $75 \%$ of Kuwaiti chickens had black eyes (Figure 3). Different eye colors were the 


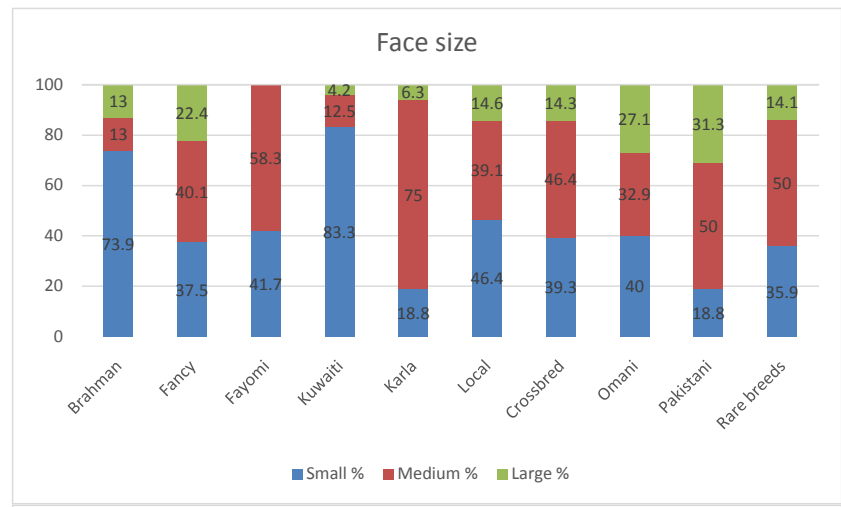

Eyes color

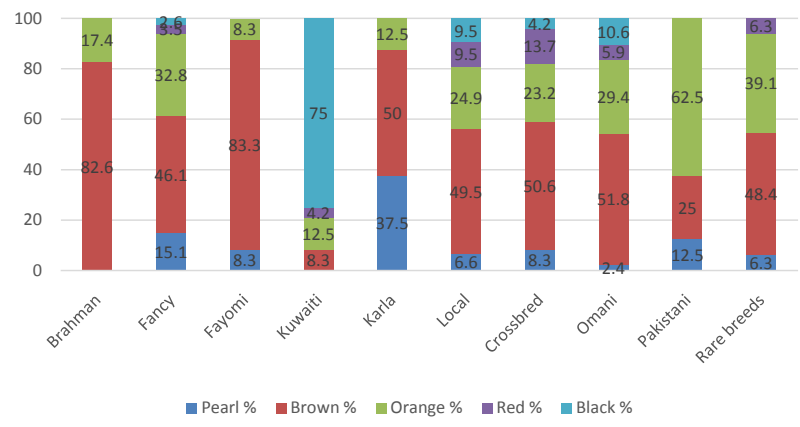

Beak color

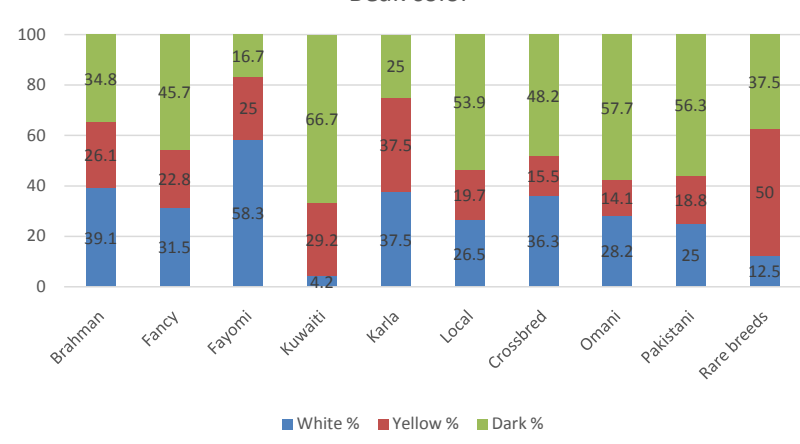

Ear-lobe color

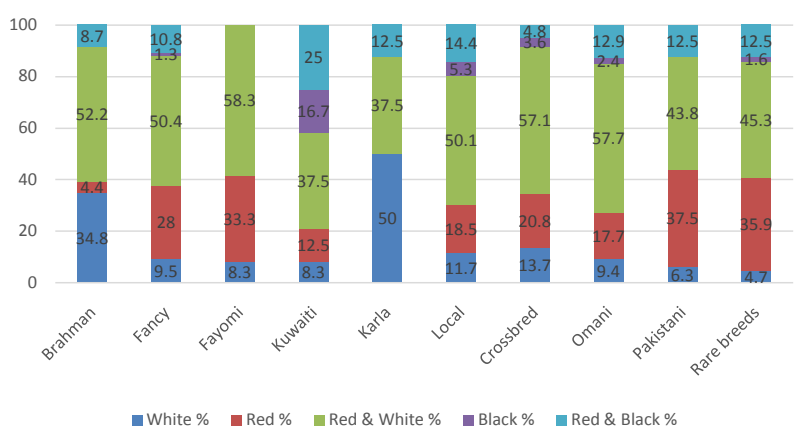

Wattle Color

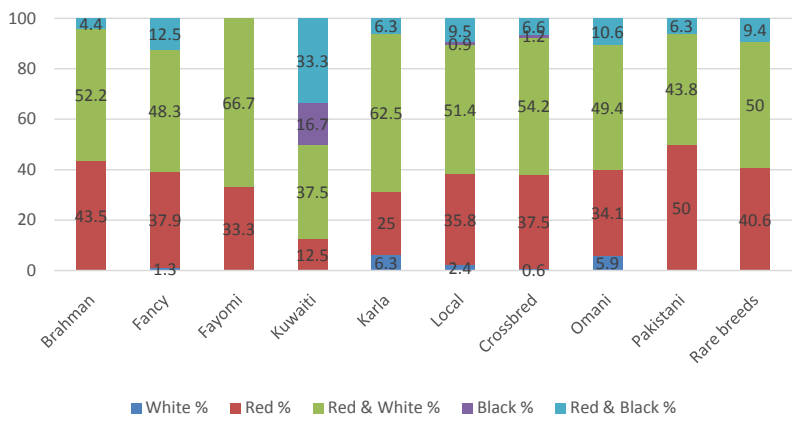

Wattle Size

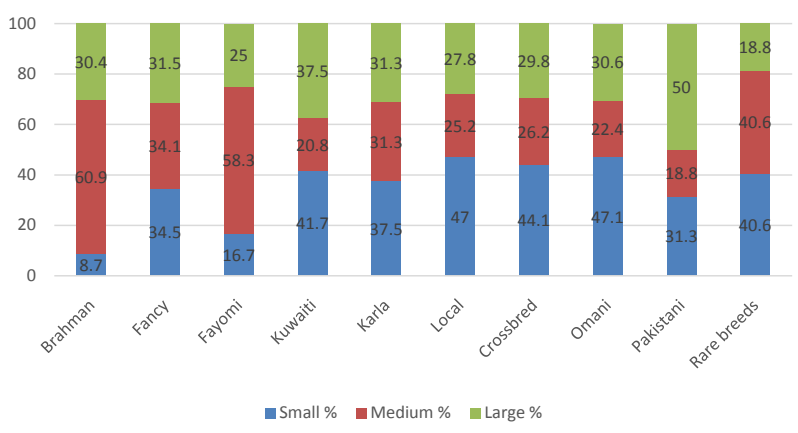

Figure 3. Face size, eye, beak color and ear-lob color and wattle color and size as affected by breed of chicken. P-value for the chi-square test $(P<0.001)$. Other breeds: uncommon breeds that were named Holland, Australian, Japanese, Habhab and Abu-Dhabi.

most prominent in different parts of the worlds; this include dark brown, orange, light brown, black and red; with high diversity [2] [3] [12] [20]. This diversity in eye color is dependent on carotenoid pigments and blood supply within the eye [26], which in consequence is related to intake and efficiency of utilization of carotenoids, genetic makeup and crossbreeding among different genotypes [13] [20].

In all VCs breeds, dark (49.7\%) beaks were more available than white (28.6\%) or yellow (21.7\%) beaks. More white beaks were available than other colors for Brahman (39.1\%) and Fayomi (58.3\%), while $66.7 \%$ of beak color for Kuwaiti were dark (Figure 3). Red and white (51.1\%) ear-lobs were more found than other ear-lob colors in all VCs breeds, though wide variation were found among different VCs breeds (Figure 3). However, black ear-lobs had the lowest fre- 
quency $(3.7 \%)$ in the whole population of VCs, except for Kuwaiti chickens which had $16.7 \%$ of black ear-lob. Kerala chickens, on the other hand, had 50\% white, $37.5 \%$ red and white, and $12.5 \%$ black and white ear-lob colors. Tashi and Dorji [9] reported different prominent earlobe colors for different genotypic groups of VCs among which were red, white, and white and red in Bhutan, while in Sri Lanka, [3] reported red ear-lob for the majority of VCs except for the crossbred chickens. However, [2] reported only 4 ear-lob colors in VCs of Ethiopia. The amount of variation in earlobe colors is related to different genetic groups [13].

The distribution of wattle colors was similar to that of ear-lob colors with some variation. Red and white (50.9\%) wattles were more available than other colors, secondly the red (36.3\%) wattles then red and black (10\%) wattles with black wattles being the least $(0.9 \%)$ in the overall VCs breeds. Local, Fancy, Omani, Kerala and crossbred chickens were not very different. Fayomi chickens had either read and white (66.7\%) or red (33.3\%) wattles, while Kuwaiti chickens had relatively high frequency of black (16.7\%) and black and white $(33.3 \%)$ wattles (Figure 3).

Small wattles $(41.9 \%)$ were more available than medium $(28.9 \%)$ and large (29.2\%) ones in the overall VCs sampled breeds. However, more frequency of large $(50 \%)$ wattles was found in the Pakistani chickens than other sizes and more medium (60.9\%) wattles were found for Brahman chickens than other sizes (Figure 3). Aklilu et al. [2] reported significant differences in wattles size among different genotypic groups of VCs. Large wattles allow for better heat loss especially in countries with hot environment and are related to gonad development and amount of sex hormones secretion [2] [15].

\section{Comb characteristics}

Most of the sampled VCs in the Emirate had single comb (82.4\%), with 11 other types and one with no comb were represented with low to very low frequencies, with significant $(P<0.01)$ differences among breeds (Figure 4$) .85 .2 \%$ of Emirati local breed had single comb with all other 11 and the no comb types were represented with less frequency than $4 \%$ for each of the types, while all Fayomi had single comb. Higher frequency of the single comb type which was also the largest in size is suggesting a natural selection advantage due to greater adaptability to hot environment conditions [12]. Pakistani chickens had either single $(75 \%)$, rose $18.8 \%$ or pea $(6.2 \%)$ comb types, also Kerala had $87.4 \%$ single $6.3 \%$ walnut and $6.3 \%$ buttercup comb types. On the other hand, Kuwaiti had $41.7 \%$ buttercup and only $29.2 \%$ single comb in addition to $16.7 \% \mathrm{~V}$-shape with spike comb and Brahman had 30.4\% V-shape, $26.1 \%$ single, $17.4 \%$ spike and $8.7 \%$ no comb. However, fewer comb types were reported by other researchers. Wani et al. [15] in Sudan and [2] in Ethiopia reported only 4 comb types in VCs with differences in frequencies among different genetic groups, while [9] reported only 3 comb types in VCs of Bhutan. Although, single comb is predominant comb type in many parts of the world, significant differences among genetic groups were reported [3] [9] [12]. However, other researchers reported different predominant comb types [8] [18]. 


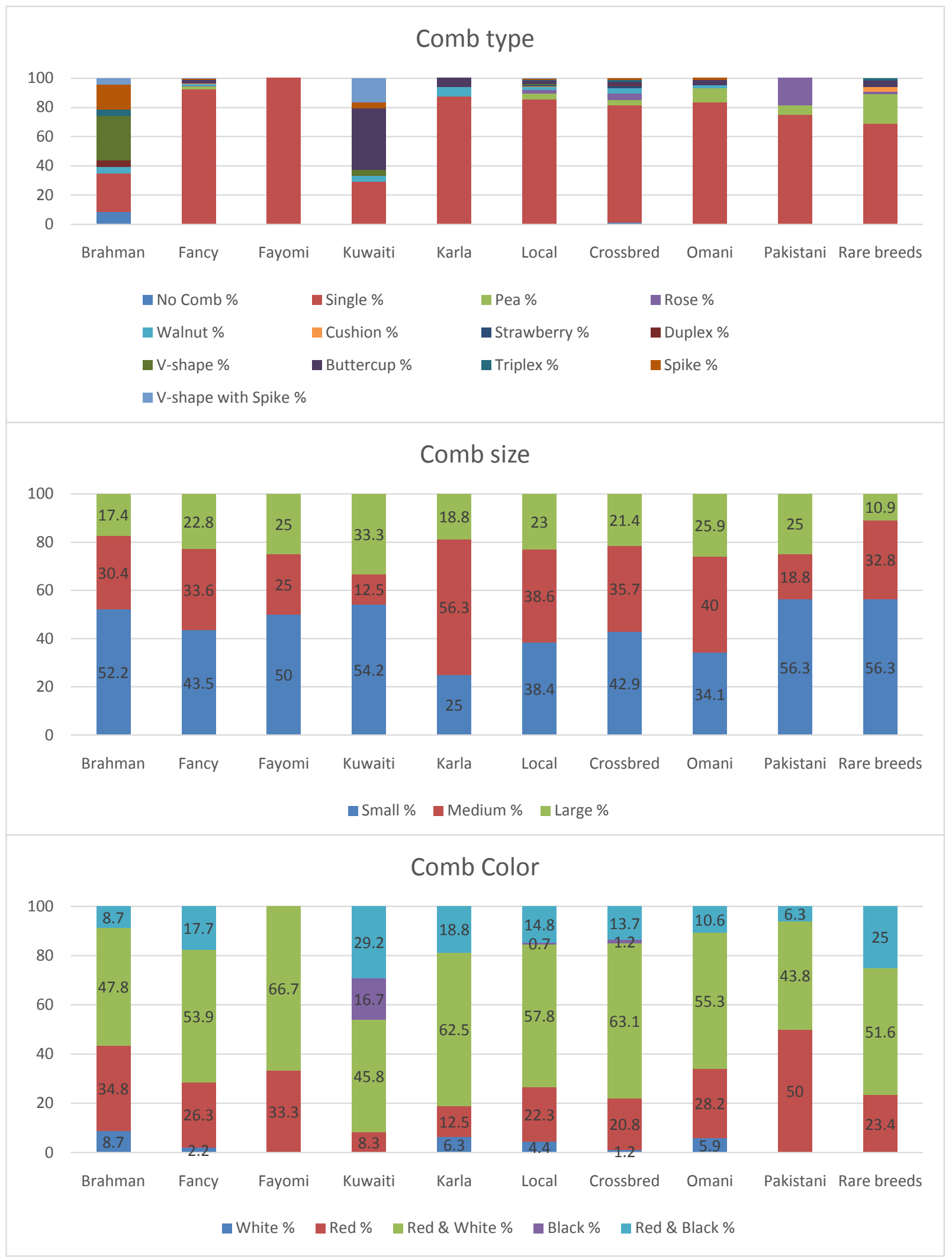

Figure 4. Comb type, size and color as affected by breed of chicken. P-value for the chi-square test $(P<0.001)$ except for comb size was not significant among breeds $(P>0.1)$. Other breeds: uncommon breeds that were named Holland, Australian, Japanese, Habhab and Abu-Dhabi. 
Small combs (41.7\%) were more available than either medium (36\%) or large (22.3\%) combs in the overall sampled population. Despite that, combs allow for better heat loss in the tropical climate of UAE [9] [12]. However, classification of comb sizes is regardless of their types, where single comb had the highest frequency. In other hot climate countries, large combs were more frequent [2] [12]. However, also in hot climate country like Ethiopia the small combs were the most frequent [18]. Although, numerical differences in frequencies of comb sizes were found among different breeds, no significant $(P>0.1)$ difference was found.

In the whole sample, red and white combs (56.7\%) were the most available, however, plain red (23.8\%) and red and black (15.5\%) were represented by high percentages, with high significant $(P<0.01)$ differences among VCs breeds (Figure 4). In Pakistani chickens, the red combs were the most available (50\%), though, red and white (43.7\%) and red and black (6.3\%) were also available. Fayomi combs were either red and white (66.7\%) or plain red (33.3\%). High percentage of black (16.7\%) and red and black (29.2\%) combs were found for Kuwaiti chickens. Wani et al. [15] reported high diversity in combs colors among and within Sudanese VCs of different genotypes.

\section{Conclusion}

In Abu-Dhabi Emirate, many VCs breeds existed (13 breeds and crossbreds), which exhibited wide phenotypic variation. This phenotypic variation reflected by the morphological characteristics of the different breeds raised in Abu-Dhabi Emirate, which considered the scientific base for future implementing of conservation and/or genetic improvement programs. Estimates of production performance and molecular based characterization of the different breeds of VCs reported in UAE under relatively improved management conditions are important before executing any genetic improvement program.

\section{Acknowledgements}

The authors are grateful to Abu-Dhabi Food Control Authority (ADFCA), Abu-Dhabi, UAE, for the financial support and to all persons who helped in achieving this study.

\section{References}

[1] FAO (2012) Animal Production and Health Guidelines No. 11. FAO, Rome.

[2] Aklilu, E., Kebede, K., Dessie, T. and Banerjee, A.K. (2013) Phenotypic Characterization of Indigenous Chicken Population in Ethiopia. International Journal of Interdisciplinary and Multidisciplinary Studies, 1, 24-32.

[3] Liyanage, R.P., Dematawewa, C.M.B. and Silva, G.L.L.P. (2015) Comparative Study on Morphological and Morphometric Features of Village Chicken in Sri Lanka. Tropical Agricultural Research, 26, 261-273. https://doi.org/10.4038/tar.v26i2.8090

[4] Muchadeyi, F.C., Sibanda, S., Kusina, N.T., Kusina, J. and Makuza, S. (2004) The Village Chicken Production System in Rushinga District of Zimbabwe. Livestock 
Research for Rural Development, 16, 6.

http://www.lrrd.org/lrrd16/6/much16040.htm

[5] Mtileni, B.J., Muchadeyi, F.C., Maiwashe, A., Phitsane, P.M., Halimani, T.E., Chimonyo, M. and Dzama, K. (2009) Characterization of Production Systems for Indigenous Chicken Genetic Resources of South Africa. Applied Animal Husbandry \& Rural Development, 2, 18-22.

[6] Dorji, N., Duangjinda, M. and Phasuk, Y. (2012) Genetic Characterization of Bhutanese Native Chickens Based on an Analysis of Red Junglefowl, Domestic Southeast Asian and Commercial Chicken Lines. Genetics and Molecular Biology, 35, 603-609. https://doi.org/10.1590/S1415-47572012005000039

[7] Tabbaa, M.J. and Hassanin, H.H. (2017) Production Systems of Village Chickens in the Abu-Dhabi Emirate, UAE. African Journal of Agricultural Research, 12, 2986-2994. https://doi.org/10.5897/AJAR2017.12457

[8] Mangesha, M. and Tsega, W. (2011) Phenotypic and Genotypic Characteristics of Indigenous Chickens in Ethiopia: A Review. African Journal of Agricultural Research, 6, 5398-5404.

[9] Tashi, T. and Dorji, N. (2014) Variation in Qualitative Traits in Bhutanese Indigenous Chickens. Animal Genetic Resources, 54, 73-77. https://doi.org/10.1017/S2078633614000071

[10] Bondoc, O.L. (1998) Biodiversity of Livestock and Poultry Genetic Resources in the Philippines. IAS-CA/UPLB and PCARRD-DOST.

[11] Alshawabkeh, K. and Tabbaa, M.J. (2001) Comparative Study on the Resistance of Three Commercial Strains and Balady (Local) Breed of Chickens to Infection with Salmonella gallinarum. Asian-Australasian Journal of Animal Sciences, 14, 96-100. https://doi.org/10.5713/ajas.2001.96

[12] Apuno, A.A., Mbap, S.T. and Ibrahim, T. (2011) Characterization of Local Chickens (Gallus Gal-Lus Domesticus) in Shelleng and Song Local Government Areas of Adamawa State, Nigeria. Agriculture and Biology Journal of North America, 2, 6-14. https://doi.org/10.5251/abjna.2011.2.1.6.14

[13] Cabarles, J.C. (2013) Phenotypic Cluster and Diversity Analysis of Native Chickens in Western Visayas, Philippines. Animal Genetic Resources, 53, 1-9. https://doi.org/10.1017/S2078633613000337

[14] FAO (2007) Global Plan of Action for Animal Genetic Resources and the Interlaken Declaration. FAO, Rome. http://www.fao.org/docrep/010/a1404e/a1404e00.htm

[15] Wani, C.E., Yousif, I.A., Ibrahim, M.E., Musa, H.H. and Elamin, K.M. (2014) Morphological, Reproductive and Productive Characteristics of Sudanese Native Chicken. Animal Genetic Resources, 54, 33-41. https://doi.org/10.1017/S2078633614000137

[16] Al-Atiyat, R. (2009) Diversity of Chicken Populations in Jordan Determine using Discriminate Analysis of Performance Traits. International Journal of Agriculture and Biology, 11, 374-380.

[17] Bett, H.K., Bett, R.C., Peters, K.J., Kahi, A.K. and Bokelmann, W. (2011) Estimating Farmers' Preferences in Selection of Indigenous Chicken Genetic Resources using Non-Market Attributes. Animal Genetic Resources Information, 49, 51-63. https://doi.org/10.1017/S2078633611000348

[18] Dana, N., Dessie, T., van der Waaij, L.H. and van Arendonk, J.A.M. (2010) Morphological Features of Indigenous Chicken Populations of Ethiopia. Animal Genetic Resources, 46, 11-23. https://doi.org/10.1017/S2078633610000652

[19] SAS Institute (2009) SAS User Guide. LOGESTIC Procedure, Cary. 
[20] Kosba, M.A., Yakout, H.M., Ebeid, T.A., Abd El-Azim, A., Shikhon, Z.H., Thieme, O. and Ahmed, Z.S. (2009) Poultry Genetic Resources Used by Small Producers. Proceedings of 5 th International Poultry Conference, Taba, 10-13 March 2009, 67-77.

[21] Cabarles, J.C., Lambio, A.L., Vega, S.A., Captain, S.S. and Mendioro, M.S. (2012) Distinct Morphological Features of Traditional Chickens (Gallus gallusdomesticus L.) in Western Visyas, Philippines. Animal Genetic Resources, 51, 73-87. https://doi.org/10.1017/S2078633612000410

[22] Mtileni, B.J., Muchadeyi, F.C., Maiwashe, A., Chimonyo, M., Mapiye, C. and Dzama, K. (2013) Influence of Socioeconomic Factors on Production Constraints Faced by Indigenous Chicken Producers in South Africa. Tropical Animal Health and Production, 45, 67-74.

[23] Al-Khalaifa, H., Al-Nasser, A., Ragheb, G., Khalil, F., Al-Bahouh, M. and Mashaly, M. (2013) Production of Local Chicken Breeds and Non-Chicken Species. Proceedings of International Congress on Advancements in Poultry Production in the Middle East and African States, Antalya, 21-25 October 2013, 1-8.

[24] Ige, A.O., Salako, A.E., Yakubu, A. and Adeyemi, S.A. (2012) Qualitative Traits Characterization of Yoruba and Fulani Ecotype Indigenous Chickens in Derived Savannah Zone of Nigeria. International Journal of Poultry Science, 11, 616-620. https://doi.org/10.3923/ijps.2012.616.620

[25] Egahi, J.O., Dim, N.I. and Momoh, O.M. (2013) The Effect of Plumage Modifier Genes on Egg Quality Indices of the Nigerian Local Chicken. Journal of Agricultural and Veterinary Sciences, 2, 4-6.

[26] Crawford, R.D. (1990) Origin and History of Poultry Species. Poultry Breeding and Genetics. Elsevier, Amsterdam, 1-42. 